\title{
O EMPIRISMO CONJECTURAL DE KANT
}

\author{
Lucas Ribeiro Vollet $^{1}$
}

\begin{abstract}
Resumo:
O presente artigo pretende apresentar a tese epistemológica de Kant na Crítica da Razão Pura como um empirismo conjectural. A parte da obra que foi enfocada nesse projeto é a Analítica Transcendental, com especial olhar para o argumento da Dedução Transcendental. Foi sugerido que a teoria dos princípios sintéticos - usados para identificar uma unidade objetiva nas representações - aponta para uma epistemologia centrada em princípios heurísticos, (embora essa conexão só fique clara quando Kant discute o uso regulativo das ideias, na Doutrina do Método). Esse apontamento será explorado através da sugestão de que a combinação de teses racionalistas e empiristas na Crítica da Razão Pura é melhor compreendida como um empirismo conjectural. Pretendemos apresentar a noção de conjectura como uma chave de leitura para entender a singularidade do complexo doutrinal de Kant na sua primeira obra do período Crítico, especialmente para explicar sua posição intermediária (entre diversas teses, como o realismo e o idealismo, o empirismo e o racionalismo, etc) e o modo como ele paga o preço para propor um realismo sem metafísica.
\end{abstract}

Palavras-chaves: Empirismo. Conjectural. Kant.

\section{THE CONJECTURAL EMPIRICISM OF KANT}

\begin{abstract}
:
The following article intends to present the epistemological thesis of Kant in the Critique of Pure Reason as a conjectural empiricism. The part of the work that was focused on this project is the Transcendental Analytic, with special focus on the argument of Transcendental Deduction. It has been suggested that the theory of synthetic principles - used to identify an objective unity in representations - points to an epistemology centered on heuristic principles, (although this connection only gets clear when Kant discusses the regulative use of ideas in the Doctrine of Method). This point will be explored through the thesis that the Critique of Pure Reason contains a conjectural empiricism. We intend to present the notion of conjecture as a key concept to understand the uniqueness of Kant's doctrinal complex in the first work of the Critical period, especially to explain his intermediate position (between empiricism and rationalism) and to explain the solution he finds in order to propose a kind of realism detached from metaphysics.
\end{abstract}

Keywords: Empiricism. Conjectural. Kant.

\section{Estratégia de exposição}

A apresentação da nossa tese de leitura será feita através da seguinte estratégia: através de seis perguntas, pretendemos dar respostas sobre 1. em que sentido é adequado dizer que a retomada do problema histórico do empirismo contextualiza os objetivos kantianos? 2. Qual a iniciativa inovadora de Kant para revisar e corrigir o empirismo? 3. O que é um empirismo conjectural? 4. Quais as vantagens dessa linha de leitura para uma discussão epistemológica sobre o empirismo? 5. Como o empirismo de

1 Possui graduação em filosofia pela Universidade Federal de Santa Catarina (2008), mestrado em Filosofia pela Universidade Federal de Santa Catarina (2011), e doutorado em Filosofia (2016) pela mesma Universidade, atuando principalmente no seguinte tema: juízo, razão prática, validade, ciência. E-mail: luvollet@gmail.com 
Kant coincide com a cena de oposição ao empirismo lógico e ao ceticismo recente (comparando com a segunda fase de Wittgenstein)? 6. Qual a consequência de uma epistemologia conjectural para a interpretação da posição filosófica da Crítica da Razão Pura?

\section{Primeira pergunta: porque o problema histórico do empirismo contextualiza os objetivos de Kant?)}

Nos textos da Crítica da Razão Pura, Kant associa o empirismo a Locke (A 269/ B 325, A 854/ B 882) e Hume (B 20). Durante sua redação da Dialética Transcendental, menciona também Epicuro, em contraste com Platão (A 471 / B 499). Contamos com as lentes do problema histórico do empirismo para contextualizar nossa discussão. A invocação do problema do empirismo antes do que o do racionalismo significa apenas que em nossa leitura demos ênfase às premissas do primeiro e ao modo como elas são afetadas, revisadas e adaptadas pela tese de Kant sobre as condições de possibilidade para qualquer experiência. Isso não significa que a crise da razão, ou o problema das pretensões da razão pura, merecem menor atenção na lista de problemas abordados pela Crítica da Razão Pura. Significa apenas que, segundo nossa perspectiva, o problema do empirismo engloba o problema da razão pura. E o engloba no seguinte sentido: a resposta racionalista se move no interior de um conjunto de premissas e questões sobre a possibilidade da experiência e o grau de influência que se deve conceder a esta na fundação do conhecimento.

Kant não deixa de reconhecer essa aproximação maior do empirismo com o problema geral do conhecimento. Segundo ele, Hume é "o filósofo que, entre todos, mais se aproximou deste problema, embora estivesse longe de determiná-lo com suficiente rigor...” (B 20). Para determinar em que sentido essa aproximação é realizada, sugerimos reelaborar o problema histórico do empirismo entendendo por ele todo o cenário filosófico envolvido na seguinte discussão: qual o grau de dependência que o nosso conhecimento tem da experiência? Durante o clímax dessa discussão no século XVII e XVIII as respostas a essa questão alternaram entre postular a independência completa dos sentidos, e a sugestão de que a razão pura tem de suplementar as limitações da sensibilidade. Ao anunciar uma fórmula para o problema geral da razão pura, na segunda edição da Introdução à Crítica da Razão Pura, Kant abrevia essa

\begin{tabular}{|c|c|c|c|c|}
\hline Revista Dialectus & Ano 5 & n. 12 & Janeiro - Julho 2018 & p. $340-352$ \\
\hline
\end{tabular}


discussão através da pergunta: como é possível o conhecimento empírico necessário e $a$ priori? Ou, como são possíveis juízos sintéticos e a priori? (B 19).

A questão não orienta uma suspeita sobre a existência desses juízos, mas questiona como são possíveis. Sua solução depende, contudo, da colocação de outra questão, que foi colocada por Kant na carta a Markus Herz de 1772 (quase dez anos antes da publicação da CRP, embora seja considerada a detonação de seu despertar Crítico): qual o fundamento da referência entre representação e objeto? Essa pergunta desencobre, a nosso ver, o problema histórico do empirismo. Se o modo como as questões são colocadas direcionam inapelavelmente para certas respostas típicas, é possível dizer que essa questão é também a responsável pelo despertar do ceticismo entre os empiristas modernos. Esse direcionamento típico é o que fez, talvez, Kant evitar o título de empirista, embora tivesse também uma teoria sobre a experiência possível que, por sua vez, evitava o ceticismo. O problema contextualizado na carta a Herz está presente tanto na procura cartesiana de um elemento de certeza indubitável no interior de nossa vida mental, quanto na pergunta lockeana sobre os elementos sensíveis mínimos de onde são derivados todos os outros conhecimentos compostos. É ela que marca a contextualização do problema abordado neste trabalho, e estrutura a resposta de Kant.

\section{Qual a inovação de Kant para corrigir e revisar o empirismo?}

Podemos reescrever a pergunta também dessa maneira: como um empirismo centrado em conjecturas dá resposta às limitações do empirismo pré-kantiano? No prefácio à Crítica da Razão Pura, Kant demonstra que o modo como essa questão é respondida determina a legitimidade da ciência empírica, ou o seu bom rumo no “caminho da razão". E ele habilmente descobre que as alternativas que o precedem são incapazes de responder a essa questão de maneira favorável à legitimidade da ciência.

A solução de Kant à questão enunciada na carta a Markus Herz só foi formulada no fim da Dedução Transcendental (B 167): ou é a experiência que possibilita os conceitos, ou os conceitos que possibilitam a experiência (quanto à forma). Para o autor tanto o racionalista quanto o empirista ignoraram a única alternativa que permitiria justificar o conhecimento empírico e a priori que compõe a ciência: a de que a própria subjetividade prescreve regras que condicionam a

\begin{tabular}{|l|l|l|l|l|}
\hline Q Rovista Dialectus & Ano 5 & n. 12 & Janeiro - Julho 2018 & p. 340-352 \\
\hline
\end{tabular}


possibilidade do objeto da experiência ${ }^{2}$. Essa resposta envolve uma subversão (chamada de revolução copernicana) do modo tradicional de colocar a questão da correlação entre representação e objeto.

O trabalho aqui apresentado explorou três maneiras como essa limitação pré-kantiana se reflete em teses subsequentes sobre a natureza da experiência. Elencamos essas três teses como: 1. A contaminação metafísica do conceito de experiência (segundo a qual o conceito de experiência depende de uma propriedade, como a de "ser doadora de certeza objetiva" ou a "indubitabilidade" que pertence à classe de ocorrências mentais oficialmente batizadas como experiência. Entendendo a metafísica como a doutrina de legislação da razão pura para controlar o que conta como conhecimento válido, sugerimos que a experiência contaminada metafisicamente é uma experiência que precisa ser qualificada com uma propriedade pública, oficial, ou protocolar, capaz de autenticá-las como doadora credenciada de certeza cognitiva) 2. A teoria pictórica (segunda a qual existe uma isomorfia estrutural entre a representação e o mundo externo ou um objeto externo, ou uma regra de semelhança e fidelidade que garante a conexão entre objeto e representação. A teoria pictórica é compatível e suplementa a tese da contaminação metafísica da experiência. Nela, a experiência aparece como uma representação com a propriedade de ser isomórfica a como o mundo realmente é, ou a propriedade de ser "semelhante a um objeto". Tal propriedade pode ser doada por uma teoria metafísica, por exemplo, a teoria de Leibniz sobre a harmonia pré-estabelecida entre máquina espiritual e o mundo externo, ou por uma teoria psicológica, por exemplo, a teoria lockeana sobre a coordenação de nossa sensibilidade e fragmentos de coisas externas. Seja qual for o caso, a conexão entre realidade e representação em uma teoria pictórica se dá a partir de uma propriedade contingente, como um milagre ou uma configuração natural e acidental de nosso aparelho sensível B 168). 3. A tese da indiferença da experiência (segundo a qual a experiência é um evento independente e sem qualquer influência para decidir a preferência por uma ou outra conexão com outras experiências. Essa doutrina pode assumir duas formas: ou a experiência não pode ser regida por leis, ou pode, mas apenas por leis não racionais -

As limitações do racionalismo e do empirismo pré-kantianos podem ser colocadas em termos simples, assim: ambos foram incapazes de prever uma qualificação sintética para a verdade necessária e $a$ priori. Tanto o racionalismo de Leibniz quanto o empirismo de Locke e Hume acreditavam que a necessidade e a qualificação a prioristica só poderia ser analítica. A experiência sensível, ou era um frágil elemento contingente dos processos inferiores da inteligência, ou apenas um conjunto de fragmentos sensíveis combinados psicologicamente.

\begin{tabular}{|l|l|l|l|l|}
\hline Qevista Dialectus & Ano 5 & n. 12 & Janeiro - Julho 2018 & p. 340-352 \\
\hline
\end{tabular}


como o hábito psicológico. A indiferença da experiência é consequência da contaminação metafísica e de uma teoria pictórica sobre a representação: isto é, a independência e indiferença de uma experiência é uma consequência do fato de que o conteúdo que ela informa depende de uma conexão contingente e gratuita com uma realidade transcendente. Nela, o objeto seria ligado à representação de maneira gratuita. Por conseguinte, a regularidade das experiências dependeria de uma premissa contingente: um milagre inicial, a presunção de uniformidade do mundo, uma configuração fisiológica/psicológica específica, etc.

A tese de Kant acrescenta a necessidade de um horizonte transcendental de regras sem o qual nenhuma experiência, sequer a corrente interna de nossas representações temporais, seria possível. A ideia de que o objeto de nossas representações é determinado por um horizonte de regras de sínteses prescritas por um sujeito filtra três alternativas de interpretação da relação entre representação e objeto:

1. um objeto não pode ser associado à representação mental mediante uma relação de semelhança pictórica, pois ele não existe como uma coisa externa que possa ser espelhada através de um órgão sensível ou intelectual.

2. Um objeto tampouco depende de uma autenticação metafísica, uma vez que a validação de uma experiência depende de sua contribuição dentro de uma estratégia heurística de investigação empírica. Assim, ele não deve nada a uma validação oficializada pela metafísica ou outra forma robusta de filosofia. Por fim,

3.um objeto só pode ser compreendido de maneira condicional, a partir de suas relações condicionais ${ }^{1}$ com outros objetos da conjectura, de maneira que há relações sintéticas e a priori entre eles e eles não podem ser entendidos de outra maneira. Um "jogo cego das representações” ou a indiferença gratuita entre dados da experiência é, para Kant, incognoscível, pelo mesmo motivo que as coisas em si são incognoscíveis: elas teriam de ser dadas de maneira incondicional como uma totalidade ou uma singularidade absoluta, (p. ex. como mônadas inteligíveis como ideias puras) ${ }^{1}$. Todas essas condições concordam com a tese célebre de que o objeto só possa ser conhecido como fenômeno, nunca como coisa em si. Ele é a resposta transcendental à alternativa psicológica e metafísica de Locke e Leibniz.

A argumentação kantiana adiciona um princípio sintético originário para garantir a recognição, a reprodução e a apreensão dos fenômenos. Esse princípio sintético é apresentado como apercepção transcendental, mas se confunde com a própria

\begin{tabular}{|c|c|c|c|c|}
\hline Rovista Dialectus & Ano 5 & n. 12 & Janeiro - Julho 2018 & p. $340-352$ \\
\hline
\end{tabular}


atividade de julgar. O que isso ensina não é que existem experiências mais válidas ou mais oficialmente autênticas devido a uma propriedade metafísica ou psicológica que existisse fora do juízo, mas sim que a validade ou autenticidade da experiência depende dos modos como ela é condicionada por essas sínteses (ou formas a priori de juízo) ${ }^{1}$. Essa é a inovação de Kant para uma teoria epistemológica empirista.

\section{O que é um empirismo conjectural?}

Estabelecido o cenário do problema, adotamos como primeira hipótese que a tese de Kant na Analítica Transcendental sobre as condições de possibilidade da experiência é um empirismo de tipo particular. Esse tipo particular é o que chamamos nesse trabalho de empirismo conjectural. Por conjectural entendemos o fato de que as condições a priori para o conhecimento determinam uma esfera paradigmática de problemas para a investigação empírica. A expressão "conjectura" representa o aspecto especulativo e o conjunto de pressuposições que guiam uma estratégia heurística para extrair respostas da natureza. A esfera paradigmática para a investigação empírica é determinada por um horizonte de questionamento da natureza.

As premissas das quais derivamos essa linha de leitura estão principalmente situadas na tese da unidade objetiva da consciência, na Dedução Metafísica e nas duas edições da Dedução Transcendental. Segundo elas, a conexão de nossas representações e seu objeto depende de um princípio sintético originário, responsável por soletrar o múltiplo em uma experiência. A experiência é apresentada como possibilitada pela faculdade de regras (A126), e a própria natureza é vista como necessariamente regular devido à prescrição de regras à natureza feita pelo sujeito ${ }^{3}$.

Esta proposta é, a princípio, uma guia para uma linha leitura. Segundo essa linha, a experiência, para Kant, adquire seu valor apenas em um contexto conjectural onde é possível avaliar a contribuição e a relevância (desta experiência) em um sistema de inter-relações necessárias e a priori $^{4}$. A sensação crua, portanto, não é ainda

3 Mas não porque "coincidiria" 3 de ser assim por uma lei metafísica ou psicológica/antropológica (B168) ${ }^{3}$ (uma questão de fato). Observando que a necessidade da regularidade natural depende, em Kant, das formas subjetivas de prescrever regras à natureza, interpretamos os argumentos da Analítica Transcendental da Crítica da Razão Pura como premissas de um empirismo conjectural. A presença do sujeito, aqui, deve ser entendida já no sentido conjectural de um foco de pesquisa, uma fonte de categorias ou formas que orientam as possíveis respostas da natureza.

4 Após grande parte da obra dedicada a expor os paradoxos e contradições transcendentais que se seguiriam de tentativas de conhecer independentes dessas condições, o autor retorna ao

\begin{tabular}{|c|c|c|c|c|}
\hline Rovista Dialectus & Ano 5 & n. 12 & Janeiro - Julho 2018 & p. $340-352$ \\
\hline
\end{tabular}


experiência da mesma forma que um simples gatilho neurológico estimulado artificialmente não foi ainda interpretado, e, portanto é apenas um dado interno absoluto e vazio (a tentativa de credenciar oficialmente esses dados através de doutrinas psicológicas ou metafísicas só pode levar a confusões entre coisa em si e fenômenos). Transformar um estímulo em referência a algo de externo é um passo que depende do contexto conjectural e das formas de questionamento que me são acessíveis enquanto sujeito dessas experiências. Mas por isso mesmo essa referência externa nunca está completamente destacada da influência subjetiva, ou do contexto conjectural de um sujeito. Uma forma mínima de idealismo persiste. Tal leitura é fiel a uma doutrina capaz de validar previsões teóricas sobre o inobservável, portanto, os juízos sintéticos a priori. Segundo essa doutrina, os limites e a extensão do conhecimento não são limitados pela acessibilidade sensível, mas por um horizonte conjectural que estrutura as possibilidades de preenchimento do juízo ${ }^{5}$.

\section{Quais as vantagens dessa linha de leitura para uma discussão epistemológica sobre o empirismo?}

Ao fundamentar um tipo sintético de necessidade, Kant acreditava oferecer um fundamento para a verdade a priori das ciências empíricas. A tese epistemológica contida na Crítica da Razão Pura justifica um modelo heurístico para procurar regularidades naturais e prever o comportamento da natureza. Acreditamos ser adequado defini-la por dois principais aspectos:

1. As possibilidades de resposta da natureza não são logicamente previsíveis (de maneira tautológica), isto é, não podemos prever apenas através de uma fórmula analítica como os eventos empíricos irão se comportar.

2. As possibilidades de resposta da natureza tampouco são sensíveis ou materialmente previsíveis, pois elas são condicionadas apenas por condições formais mínimas de previsibilidade: assim, por exemplo, um objeto não pode ocorrer sem uma posição no tempo, mas isso não nos permite prever que coisa ocorreu antes ou depois apenas através da reunião de dados sensíveis. Sem a contribuição espontânea da

desenvolvimento de uma linha compatível com essa leitura na Doutrina do Método, onde apresenta a metodologia de acesso ao conhecimento objetivo como uma heurística que usa ideias apenas com um propósito de sistematização do conhecimento.

5 Qualificar o empirismo kantiano dessa maneira envolve, naturalmente, a tese suplementar de que as condições do conhecimento enunciadas pelo autor sejam conjecturais. Essa abordagem é fiel à revolução copernicana enunciada por Kant, que descreve o sujeito e o modo como este interroga a natureza como o novo centro do condicionamento do conhecimento objetivo.

\begin{tabular}{|l|l|l|l|l|}
\hline Q Rovista 2 Dialectus & Ano 5 & n. 12 & Janeiro - Julho 2018 & p. 340-352 \\
\hline
\end{tabular}


construção da regra feita pelo sujeito, os meros dados sensíveis não passam de um múltiplo sem poder informativo ou cognitivo independente. E a construção subjetiva é sempre mais do que mera imaginação ou criação gratuita: ela tem de ser limitada pelas possibilidades estruturais anexadas a essa condição subjetiva, que, na obra de Kant, são marcadas pelas categorias ou conceitos puros.

Essas duas condições coincidem com a enunciação de um tipo intermediário de necessidade ou previsibilidade: que Kant chama de sintética. O autor usou essa expressão para se referir a todo ato de produção do conhecimento determinado pela espontaneidade de ligar dados materiais. Em nossa leitura, isso enfatiza o aspecto criativo e espontâneo do sujeito na produção heurística do horizonte objetivo. A teoria das sínteses a priori de Kant tece um pano de fundo para a adaptação dos dados materiais às nossas formas de conhecer, mas não seleciona credenciais psicológicas oficiais para qualificar a ocorrência dos dados. Ele não as seleciona nem analiticamente, através de fórmulas lógico-semânticas, e nem sensivelmente, através de dados psicológicos. Os tipos de conjectura que determinam nosso horizonte de possibilidades objetivas determinam condições mínimas para a investigação da natureza. Mas eles não influenciam as respostas e nem selecionam o que conta como resposta credenciada através da adaptação a uma fórmula ou uma teoria psicológica específica. O que resta de previsível no comportamento empírico, na verdade, é meramente um produto da espontaneidade do sujeito na produção da experiência. E isso significa: é o risco ou aposta conjectural subjetivo que determina os limites do que se pode chamar de horizonte objetivo. Em outras palavras, a previsibilidade empírica não é vidência miraculosa. Ela sequer é infalível. Ela apenas garante um horizonte de risco tolerável para a prática humana.

A necessidade da experiência dentro de um horizonte conjetural explica, assim, os princípios sintéticos a priori ${ }^{6}$. Uma epistemologia conjectural explica o conhecimento como uma meta de aproximação à verdade através de estratégias de aquisição dos dados empíricos. Defendemos que a tese da unidade objetiva do conhecimento e o sistema de princípios de uma lógica transcendental é uma epistemologia desse tipo. Ela explica a necessidade das leis usadas para compreender a

6 Essa explicação dá uma alternativa tanto à necessidade meramente baseada em fórmulas, que tenta usar formas lógicas analíticas como organon técnico de interpretação para extrair verdades empíricas, quanto à necessidade meramente fundada em princípios psicológicos ou antropológicos que respondem apenas à questão quid facti.

\begin{tabular}{|l|l|l|l|l|}
\hline Rovista Dialectus & Ano 5 & n. 12 & Janeiro - Julho 2018 & p. 340-352 \\
\hline
\end{tabular}


natureza através de uma heurística, e os princípios sintéticos são interpretados como formas de uma estratégia para resolução de problemas. Essa é uma epistemologia parcialmente realista e parcialmente falibilista. O falibilismo ilimitado é visto por Kant como um contrassenso, uma vez que pressupõe a existência de uma ignorância incondicional, independente de condições paradigmáticas mínimas. Essa ignorância é impossível, pois ela teria de ser independente das próprias questões e perguntas cujas respostas ela ignora. O realismo ontológico ou transcendental, por sua vez, precisaria pressupor um conhecimento de coisas incondicionais, que ocorreriam fora das mesmas condições paradigmáticas. Para Kant, o conhecimento empírico é regido por leis necessárias, porém, não há nenhum teto epistemológico baseado em ideias puras ou em uma autoridade racional que controle ou legisle definitivamente sobre as verdades da ciência empírica. A ignorância limitada pelas condições mínimas subjetivas é o que permite que nosso conhecimento empírico seja, por um lado, falível, mas - por outro passível de seguir uma trilha objetiva esquemática baseada na própria estrutura subjetiva.

\section{Qual a consequência de uma epistemologia conjectural para a interpretação da posição filosófica da Crítica da Razão Pura?}

A resposta de Kant implica o argumento idealista transcendental de que os objetos de nossas representações são meros fenômenos. Se considerarmos o objeto da representação como mero fenômeno, isto é, coisas espaço e temporalmente representáveis, e não coisas em si, então eliminamos o pseudoproblema contido no conflito moderno entre racionalistas e empiristas. Esse pseudoproblema aparecia quando o "a priori" do conhecimento era visto como uma propriedade doada miraculosamente por deus, ou oficialmente credenciada por nossos sentidos. Se apenas essas duas opções fossem possíveis, seria natural que cedêssemos ou ao dogmatismo ou ao ceticismo. Com o novo modo de abordagem kantiano, entretanto, não há problema algum com a conexão a priori entre experiências, porque nesse caso o que há de a priori no conhecimento são apenas as condições de possibilidade de sua doação intuitiva (espaçotemporal). Não há necessidade de buscar um dado contingente cosmológico sobre a uniformidade do mundo ou sobre a coincidência miraculosa entre nossa mente e o mundo externo. Dessa maneira, o mero fenômeno de Kant equivale ao objeto de uma experiência que não é estabelecido nem a partir de uma propriedade pictórica

\begin{tabular}{|l|l|l|l|l|}
\hline Q Rovista Dialectus & Ano 5 & n. 12 & Janeiro - Julho 2018 & p. 340-352 \\
\hline
\end{tabular}


(isomorfia/a semelhança, etc), e nem a partir de uma seleção metafísica do que autentica a validade cognitiva da experiência. Este enfático conselho para que se considere os objetos como meros fenômenos é a base estratégica empregada para garantir a conexão a priori entre experiências. Posto que a conexão de nossas representações e meros fenômenos não precisa pressupor nenhum fato contingente ou miraculoso que justifique uma ponte contingente entre uma vida mental interior e um mundo exterior, essa conexão só pode ser compreendida em um sistema de relações necessárias entre outros fenômenos, a partir de leis e conceitos puros. É bem sabido que o que Kant entende por fenômeno não é o simples objeto de uma sensibilidade humana ou uma aparência enganosa e incompleta, mas o objeto de uma experiência possível conforme é um produto empírico do entendimento, (esse entendido como faculdade de regras). Isso é o mesmo que dizer que o fenômeno não é uma percepção, mas o produto esquematizado de categorias puras. Considerar o objeto da representação como mero fenômeno é idêntico a considerar o objeto da representação como mero esquema de possibilidades de preenchimento empírico. Sua natureza é meramente esquemática, como um princípio de síntese que serve de regra para a aquisição discursivamente articulada da experiência. Ele é, portanto, o que chamaríamos aqui, em uma nova paráfrase, de "objeto de um horizonte conjectural paradigmático". Entre um conceito e seu preenchimento intuitivo, ou entre um juízo e seu objeto, não existe nenhum fato contingente que autentique ou autorize a correlação (como a natureza antropológica dos seres humanos), mas apenas um conjunto paradigmático de possibilidades heurísticas para orientar uma investigação empírica.

\section{Conclusão: O sujeito e a Realidade}

Se nossa interpretação é correta, o empirismo conjectural sugere uma explicação epistemológica para a posição anti-metafísica de Kant. Uma epistemologia parcialmente realista e parcialmente falibilista, que confia em princípios de sistematização meramente heurísticos, é a contrapartida de uma teoria filosófica sem compromissos ontológicos ou metafísicos robustos. A falta de cognoscibilidade das coisas em si é explicada como o equivalente a dizer que qualquer objeto que se encontre fora do horizonte de possibilidades determinado pelo interrogatório subjetivo (da natureza) é incognoscível.

\begin{tabular}{|c|c|c|c|c|}
\hline Rovista Dialectus & Ano 5 & n. 12 & Janeiro - Julho 2018 & p. $340-352$ \\
\hline
\end{tabular}


Isso nos leva à nossa última questão, que acompanha a conclusão: como a leitura oferecida por essa tese posiciona a Crítica da Razão Pura do ponto de vista filosófico? O caráter meramente especulativo e hipotético do conhecimento é, de certa forma, o custo de uma epistemologia que não pode pedir ajuda à metafísica e à ontologia. Desta forma, o empirismo conjectural é compatível com um realismo sem doutrinas metafísicas: um realismo meramente empírico. Ao mencionar objetos que duram no tempo, que tem um grau de intensidade, e cujo movimento ocorre de acordo com leis regulares, Kant se refere ao objeto tempo e espacial. Lembremos agora que para Kant tempo e espaço são formas de toda representatividade intuitiva. A espaçotemporalidade de um objeto é, portanto, equivalente à sua posição específica dentro de um campo de perspectiva subjetiva. Apenas os objetos representáveis espaço e temporalmente e, portanto, que mantém uma relação de dependência com um tipo de perspectiva ou direção investigativa, somente esses tem duração, realidade, continuidade, e são capazes de ser representados numericamente em uma ordem cardinal, etc. O realismo empírico de Kant (que é, também, um idealismo transcendental) é um tipo de tese sobre a dependência das coisas e o sujeito. Essa dependência deve ser entendida, por sua vez, como a necessidade de um princípio de preferência que determina uma localização empírica, a individuação objetiva (A 263 / B 319), e uma distinção objetiva (A 197/ B 242). A contribuição do sujeito não é correspondente a um papel de mero observador passivo, que por sua mera presença faria o objeto surgir. $\mathrm{O}$ seu papel é o de centro especulativo que determina o alcance de uma aposta cognitiva, ou uma preferência prática, que permite avaliar a diferença de compatibilidade e incompatibilidade entre juízos empíricos que versem sobre ordens temporais ou posições espaciais. Em outras palavras, o sujeito é responsável por individuar o objeto, o distinguindo de outros objetos tempo e espaciais. Essa distinção se reflete nos tipos de condições de verdade para proposições empíricas sobre objetos espaço-temporais e permite instituir um tecido (não-lógico formal) de dependência necessária entre proposições de tipos sintéticas.

\section{REFERÊNCIAS}

ABELA, P. Kant's empirical realism. Clarendon Press, 2006.

ALLISON, H. Kant's transcendental idealism. Yale University Press, 2004.

AMERIKS, K. Kant's elliptical path. Oxford University Press, 2012.

\begin{tabular}{|c|c|c|c|c|}
\hline Q Rovista Dialectus & Ano 5 & n. 12 & Janeiro - Julho 2018 & p. $340-352$ \\
\hline
\end{tabular}


BENNET, J. Kant's dialectic. Cambridge University Pres, 1974

BENNETT, J. Strawson on Kant. Philosophical Review, n. 77, p. 340 - 349, 1968.

BEISER, Frederick. German idealism: the struggle against subjectivism 1781-1801. Londres: Harvard University Press, 2002.

BIRD, G. The revolutionary Kant. Carus Publishing Company, 2006.

BONACCINI, J. Kant e o problema da coisa em si no idealismo alemão: sua atualidade e relevância para compreensão do problema da Filosofia. Rio de Janeiro: Relume Dumará, 2003.

CAYGILL, H. Dicionário Kant. Rio de Janeiro: Jorge Zahar, 2005.

GREEN, G. The aporia od inner sense: the self-knowledge of reason and the critique of metaphysics in Kant. Brill, 2010.

GUYER, P. Kant and the claims of knowledge. Cambridge University Press, 1987.

HANNA, R. Kant e os fundamentos da filosofia analítica. São Leopoldo: Editora Unisinos, 2004.

KANT, I. Crítica da Razão Pura. Lisboa: Fundação Calouste Gulbenkian, 2001.

KANT, I. Prolegômenos a toda futura metafísica que queira apresentar-se como ciência. Edições 70, 2008.

KITCHER, P. Kant's transcendental psychology. Oxford: Oxford University Press, 1990.

LOUDEN, R. Kant's human being: essays on his theory of human nature. New York: Oxford University Press, 2011.

LANGTON, R. Kant humility: our ignorance of things in themselves. Oxford University Press, 2008.

LONGUENESSE, B. Kant and the capacity to judge. Princeton University Press, 1998.

MAKKREEL, R.A. Kant on the scientific status of psychology, anthropology, and history. In: kant and the sciences, ed. Eric Watkins. New York: Oxford University Press, 2001. p. 185-201

MOSSER, K. Necessity and possibility: the logical strategy of Kant's critique of pure reason. Washington: The Catholic University of America Press, 2008.

PIPPIN, R. B. Kant's theory of form: an essay on the critique of pure reason. Yale University Press, 1982.

SCHRADER, George. The Review of Metaphysics, Vol. 4, No. 4 (Jun., 1951), pp. 507-536.

STRAWSON, P. The bounds of sense: an essay on Kant's Critique of pure reason. London, Methuen \& Co. Ltd.; New York, Barnes \& Noble, Inc., 1966.

WAXMAN, W. Kant's model of the mind: a new interpretation of transcendental idealism. Oxford University Press, 1991.

\begin{tabular}{|c|c|c|c|c|}
\hline Revista Dialectus & Ano 5 & n. 12 & Janeiro - Julho 2018 & p. $340-352$ \\
\hline
\end{tabular}


WOOD, A.; GUYER, P.; ALLISON, H. E. Debating allison on transcendental idealism. Kantian Review, v. 12, p. 1 - 39, Jul, 2007.

\begin{tabular}{|c|c|c|c|c|}
\hline Qovista Dialectus & Ano 5 & n. 12 & Janeiro - Julho 2018 & p. $340-352$ \\
\hline
\end{tabular}

